\title{
MIGRAÇÃO HAITIANA E APATRIDIA NA REPÚBLICA DOMINICANA: INTERSECÇÕES ENTRE RACISMO E COLONIALIDADE
}

\author{
HAITIAN MIGRATION AND STATELESSNESS IN THE DOMINICAN \\ REPUBLIC: INTERSECTIONS BETWEEN RACISM AND COLONIALITY
}

\author{
Karine de Souza Silva \\ Universidade Federal de Santa Catarina - UFSC - (Florianópolis, Santa Catarina, Brasil) \\ Luísa Milioli de Amorim \\ Universidade Federal de Santa Catarina - UFSC - (Florianópolis, Santa Catarina, Brasil) \\ Recebimento: 17 out. 2018 \\ Aceitação: 14 maio 2019
}

\begin{abstract}
Como citar este artigo / How to cite this article (informe a data atual de acesso / inform the current date of access):
SILVA, Karine de Souza; AMORIM, Luísa Milioli de. Migração haitiana e apatridia na República Dominicana: intersecções entre racismo e colonialidade. Revista da Faculdade de Direito UFPR, Curitiba, PR, Brasil, v. 64, n. 2, p. 9-35, maio/ago. 2019. ISSN 2236-7284. Disponível em: https://revistas.ufpr.br/direito/article/view/62391. Acesso em: 31 ago. 2019. DOI: http://dx.doi.org/10.5380/rfdufpr.v64i2.62391.
\end{abstract}

\section{RESUMO}

O objetivo deste artigo é atestar que a generalização do status de apátrida na República Dominicana é um dos resultados da exploração colonial que teve a raça como elemento estruturante e que, por sua vez, provocou a formação de uma discursividade de repulsa ao povo haitiano. Esta abordagem é inédita porque se utiliza das epistemologias decoloniais para constatar que o complexo labirinto jurídico que motivou a desnacionalização de cidadãos outrora dominicanos, e que tem negado o direito à nacionalidade para muitos outros, faz parte de um amplo panorama histórico de abjeção contra haitianos que é respaldada por uma ideologia anti-haitiana fundada na discriminação racial contra as populações da diáspora africana. Nesse sentido, confirma-se que as relações hierarquizadas de raça introduzidas e estruturadas desde a colonização seguem operando na atualidade, com novas vestimentas.

\section{PALAVRAS-CHAVE}

Migração haitiana. Haiti. República Dominicana. Apatridia. Colonialidade.

\begin{abstract}
The purpose of this article is to attest that the generalization of statelessness status in the Dominican Republic is one of the results of colonial exploration which had the race as a structuring element and that, in turn, provoked the formation of a discursivity of repulsion toward the Haitian people. This approach is unprecedented because it uses decolonial epistemologies to ascertain that the complex legal labyrinth that motivated the denationalization of erstwhile Dominican citizens, and that has denied the right to nationality for many others, is part of a wide historical panorama of abjection against Haitians which is supported by an anti-Haitian ideology grounded on racial discrimination against the populations of the African diaspora. In this sense, it is confirmed that the hierarchical
\end{abstract}


relations of race introduced and structured since colonization proceed to operate nowadays with new garments.

\section{KEYWORDS}

Haitian migration. Haiti. Dominican Republic. Statelessness. Coloniality.

\section{INTRODUÇÃO}

A República Dominicana (RD) é considerada como o exemplo máximo da apatridia nas Américas. Em setembro de 2013, o Tribunal Constitucional do país revogou retroativamente a nacionalidade de milhares de pessoas nascidas entre 1929 e 2010, dando lugar a uma situação de apatridia que afetou cerca de 200.000 descendentes de haitianos. A Sentença 168/13, no entanto, não foi um ato isolado, mas uma expressão evidente de um longo processo político-jurídico de aversão aos indivíduos de ascendência haitiana.

Na RD, embora seja o lar de um dos maiores contingentes de imigrantes haitianos, é onde se verifica o maior desenvolvimento de políticas hostis contra essa população, em específico. Esta situação tem como pano de fundo a convivência acrimoniosa entre as duas nações, resultante, sobretudo, da colonização e da independência que incidiram na formação de dois Estados culturalmente diferenciados e que protagonizaram vários eventos conflituosos.

O objetivo deste artigo é atestar que a generalização do status de apátrida na República Dominicana é um dos resultados da exploração colonial que teve a raça como elemento estruturante e que, por sua vez, provocou segregações entre haitianos e dominicanos. Esta abordagem é inédita porque avalia o tema com o auxílio das epistemologias críticas decoloniais e pós-colonais. A base teórica permitiu constatar que o complexo labirinto jurídico que motivou a desnacionalização de cidadãos outrora dominicanos, e que tem negado o direito à nacionalidade para muitos outros, faz parte de um amplo panorama histórico de abjeção contra haitianos que é respaldada por uma ideologia anti-haitiana fundada na discriminação racial contra as populações da diáspora africana. Nesse sentido, verifica-se que as relações hierarquizadas de raça introduzidas e estruturadas desde a colonização persistem na atualidade, com novas roupagens.

Para a concretização do objetivo proposto, o trabalho foi dividido em três partes: o primeiro tópico expõe a historiografia dos deslocamentos de haitianos para a $\mathrm{RD}$, bem como os vieses da política migratória que provocou a crise da apatridia. O segundo item relaciona o surgimento da rivalidade dominicana-haitiana e das tensões étnico-raciais aos processos de colonização e independência na ilha de Hispaniola. Por fim, revela-se que a construção de uma discursividade antihaitiana fundamentou as ações destinadas à interdição da nacionalidade aos haitianos, como uma 
tentativa de negar o pertencimento àqueles que se considera inferior segundo a lógica da modernidade colonial.

\section{MIGRAÇÃO HAITIANA E APATRIDIA NA REPÚBLICA DOMINICANA}

O status de apatridia dos descendentes de haitianos nascidos na República Dominicana (RD) tem suas raízes nas grandes ondas de migração laboral desses povos para o país vizinho ao longo do século XX. Com a expansão da agricultura e o crescimento da indústria açucareira na RD, a força de trabalho haitiana tornou-se o recurso humano mais importante na realização dessa atividade agrícola e, por muito tempo, o contingente migratório mais destacado do país (MÁRQUEZ, 2012).

Em um primeiro momento, a mão de obra haitiana foi estimulada durante a ocupação estadunidense que, a partir de 1919, passou a empregar um sistema de contratos regulados para a atração de braceros - ou seja, trabalhadores do corte de cana-de-açúcar. A ditadura instalada por Leónidas Trujillo (1930-1961), por sua vez, tratou a migração haitiana como caso de segurança nacional, sujeitando-a a uma política discriminatória, baseada na raça e na nacionalidade, que motivou os princípios do anti-haitianismo (MÁRQUEZ, 2012). Por lei, buscou-se conter a contratação de haitianos para os canaviais: a força de trabalho da indústria açucareira deveria ser composta por, ao menos, $70 \%$ de dominicanos. Na prática, contudo, ao passo que os trabalhadores dominicanos, no geral, recusavam-se a efetuar o corte da cana - por ser um serviço cansativo e mal remunerado -, a imigração haitiana passou a ser vista como um mal necessário, e não mais como uma ameaça (FERGUSON, 2003). Assim, deu-se início à assinatura de uma série de acordos bilaterais os convenios - entre a RD e a República Haitiana, que levaram ao aumento sem precedentes de braceros provenientes do Haiti nos bateyes ${ }^{1}$. A ditadura trujillista, portanto, foi paradoxalmente "antihaitiana e dependente” da migração dessa população (FERGUSON, 2003, p. 10).

Os braceros não possuíam a documentação necessária para regularização migratória segundo as normas dominicanas, uma vez que a grande maioria recebia unicamente um contrato de trabalho temporário, válido apenas dentro dos bateyes onde trabalhavam (WOODING; MOSELEYWILLIAMS, 2004). Além disso, a maioria dos haitianos ingressava na RD sem documentos de identificação, e não se registrava no Consulado do Haiti - não sendo oficialmente reconhecidos como residentes em solo dominicano. Estima-se que havia entre 500 mil e 700 mil haitianos no país em 1999, e que apenas 5\% destes tinham documento de identificação. Em consequência, não dispunham

\footnotetext{
${ }^{1}$ Local de assentamentos de trabalhadores da indústria açucareira.
} 
de direitos básicos: viviam em condições de superlotação, com pagamento impróprio, sem acesso à água potável, eletricidade e saneamento básico, ou seja, submetidos à marginalização. Em suma, a população migrante, que abandonara seu país na expectativa de melhores condições de vida, passara a residir no destino numa situação de pobreza, muitas vezes, ainda mais exacerbada (COMISSÃO INTERAMERICANA DE DIREITOS HUMANOS, 1999; FERGUSON, 2003).

Alguns haitianos permanecem nos bateyes até mesmo na época do ano em que não havia colheita. Assim, essas populações migrantes passaram a se estabelecer de forma contínua nos campos de trabalho, apesar de os mesmos são terem sido projetados para a moradia permanente anual dos trabalhadores, nem de famílias. De qualquer forma, alguns imigrantes iam acompanhados por seus cônjuges, outros se casavam no local e, dessa forma, constituíam família no país anfitrião (FERGUSON, 2003).

A situação de irregularidade foi, por fim, herdada pelos seus descendentes, que, mesmo quando nascidos em terreno dominicano, não obtinham acesso a documentos de identificação, supostamente porque seus pais não possuíam documento válido. Foi assim que a irregularidade documental passou a se constituir o maior problema enfrentado atualmente pela migração haitiana na RD (COMISSÃO INTERAMERICANA DE DIREITOS HUMANOS, 1999).

Desde 1844 a atribuição de nacionalidade dominicana opera segundo o princípio do jus soli. O comando regulatório definia que eram considerados dominicanos todos aqueles que nasceram no território nacional, exceto “os filhos de estrangeiros residentes no país em representação diplomática”. Contudo, a partir da promulgação da Constituição de 1929 foi introduzida mais uma exceção, que se refere aos estrangeiros “em trânsito” (REPÚBLICA DOMINICANA, 1994, Art. 11).

Entre 1950 e 1990 a aplicação da norma se deu de maneira variável, o que possibilitou a concessão de nacionalidade a algumas crianças de ascendência haitiana. Entretanto, no final do século $\mathrm{XX}$, os oficiais de registro civis passaram a impossibilitar severamente o registro de nascimento dos filhos de imigrantes considerados “transitórios" - apesar de estes residirem na RD há anos (COMISSÃO INTERAMERICANA DE DIREITOS HUMANOS, 1999). Tal aplicação da norma era equivocada, já que, segundo a Lei de Migração de 1939, o conceito de “em trânsito” estava circunscrito a estrangeiros que adentravam em território dominicano “com o propósito principal de prosseguir viagem através do país com destino ao exterior”, e ali permaneciam por um período não superior a dez dias (CONGRESO NACIONAL DE LA REPÚBLICA DOMINICANA, 1939). Dessa forma, em tese, não caberia o uso de tal exceção para a concessão de nacionalidade dominicana a filhos e filhas de haitianos. 
Em 2004, a RD revogou a Lei de Migração nº 95 de 1939. O Art. 36 da nova Lei Geral de Migração ampliou a categoria de estrangeiros em trânsito, incluindo não residentes, em especial, para fins de aplicação do Artigo 11 da Constituição, e abdicou do limite de estada de 10 dias. Na categoria não residentes, no inciso 5 , fora abarcada a condição de trabalhadores temporários - inclusive para a indústria açucareira (CONGRESO NACIONAL DE LA REPÚBLICA DOMINICANA, 2004).

A Lei de Migração de 2004 estabeleceu a emissão de certificados de nascimento de cor rosa, ou seja, diferenciados, para tais crianças, e instituiu o chamado "Livro do Estrangeiro" onde seriam registrados os menores cujos pais se caracterizassem como "não residentes" no momento do nascimento, identificando-os explicitamente como estrangeiros (CONGRESO NACIONAL DE LA REPÚBLICA DOMINICANA, 2004, art. 28). Assim, a ausência de uma certidão de nascimento de cor branca - ou seja, dominicana - impedia a aquisição da 'cédula de identidade e eleitoral' e, por conseguinte, interditava o acesso à nacionalidade dominicana, uma vez que este direito não era conferido a tais pessoas. Ademais, a normativa foi aplicada de forma retroativa, uma vez que promoveu a suspensão de certidões de nascimento já emitidas. Em resumo, a residência regularizada dos genitores passou a se constituir como requisito essencial para a aquisição da nacionalidade dominicana dos filhos de estrangeiros. Essa reformulação legislativa impactou principalmente os descendentes de trabalhadores “temporários” haitianos, condenando-os à apatridia.

Em 2005 essa situação chegou ao conhecimento da Corte Interamericana de Direitos Humanos, por meio do caso das meninas "Yean e Bosico vs. República Dominicana”. No seu Acórdão, o Tribunal entendeu que a RD violara os direitos à igualdade, à não discriminação, à nacionalidade, à personalidade jurídica e à proteção especial das crianças, ao recusar-se a emitir as certidões de nascimento e ao impedi-las de exercerem seus direitos de cidadania, devido à sua ascendência. Ao agir de modo discriminatório, o Estado submeteu as crianças à situação de apatridia, impondo-lhes um limbo jurídico de “contínua vulnerabilidade” (CORTE INTERAMERICANA DE DIREITOS HUMANOS, 2005, p. 64). Mesmo diante da condenação da Corte e da reprovação ostensiva de Organizações Internacionais governamentais e não governamentais - nomeadamente, a ONU (OHCHR, UNICEF, ACNUR), Anistia Internacional, Human Rights Watch, entre outras -, a RD não se mostrou disposta a resolver a situação.

Ante alegações de inconstitucionalidade da Lei de Migração de 2004, em janeiro de 2010, o Estado incorporou uma exceção ao regime jus soli na nova Constituição. O artigo 18.3 da nova Carta Magna dispôs que são dominicanas e dominicanos:

pessoas nascidas no território nacional, com exceção dos filhos e filhas de [...] estrangeiros que se encontrem em trânsito ou residam ilegalmente em território 
dominicano. Qualquer estrangeiro ou estrangeira definido como tal pelas leis dominicanas é considerado uma pessoa em trânsito (REPÚBLICA DOMINICANA, 2010, art. 18, grifo nosso).

De modo explícito, pela primeira vez, a Constituição dominicana bloqueou a possibilidade de concessão de nacionalidade aos descendentes de imigrantes indocumentados. Nota-se, contudo, que, consoante o disposto no Art.18.2, eram considerados nacionais "aqueles que gozam de nacionalidade dominicana antes da entrada em vigor” do texto constitucional (REPÚBLICA DOMINICANA, 2010).

Em setembro de 2013, o Tribunal Constitucional da República Dominicana prolatou a Sentença TC/0168/13, em resposta ao recurso impetrado por Juliana Deguis Pierre, que teve o seu pedido de emissão de 'cédula de identidade e eleitoral' negado em 2008 porque "seus sobrenomes eram haitianos” - apesar de ter nascido em território dominicano em 1984 e de possuir sua certidão de nascimento (TRIBUNAL CONSTITUCIONAL DE LA REPÚBLICA DOMINICANA, 2013). O Tribunal reafirmou a decisão ao reputar que a situação da demandante correspondia à exceção contida na Constituição de 1966 - vigente na data de seu nascimento - referente aos filhos de estrangeiros em trânsito nascidos no país, uma vez que seus pais eram haitianos que, na ocasião, não possuíam cédulas de identificação pessoal e, portanto, deveriam ser considerados como "trabalhadores temporários” e, consequentemente, em trânsito (TRIBUNAL CONSTITUCIONAL DE LA REPÚBLICA DOMINICANA, 2013, p. 66).

Além disso, o Acórdão de 2013 determinava que a Junta Central Eleitoral (JCE) efetuasse uma “auditoria minuciosa dos livros-registros do Registro Civil da República”, a fim de identificar todos os indivíduos “inscritos irregularmente por carecer das condições requeridas pela Constituição da República para a atribuição da nacionalidade dominicana por jus soli”, e que fizesse novo registro e qualificasse como estrangeiros os nascidos depois de 21 de junho de 1929 - outrora considerados nacionais dominicanos (TRIBUNAL CONSTITUCIONAL DE LA REPÚBLICA DOMINICANA, 2013). O entendimento foi de que estes nunca tiveram direito à nacionalidade e, portanto, deveriam ser despojados dela com efeitos retroativos. A decisão teve um impacto significativo, pois afetou cerca de 200.000 pessoas de ascendência haitiana (ALTO COMISSARIADO DAS NAÇÕES UNIDAS PARA REFUGIADOS, 2015).

Em resposta às contínuas críticas de atores internacionais, Santo Domingo buscou limitar o impacto da Sentença 168/13. Inicialmente, o Plano Nacional de Regularização de Estrangeiros (PNRE) estabeleceu as condições para a regularização migratória de estrangeiros que se encontravam indocumentados (PRESIDENCIA DE LA REPÚBLICA DOMINICANA, 2013). Por sua vez, a Lei 
Especial de Naturalização previa, primeiramente, o reconhecimento dos documentos dos indivíduos cujos nascimentos foram contabilizados em registro dominicano ${ }^{2}$ e, também, para aqueles não registrados, a possibilidade de acesso ao processo de naturalização especial contemplado em legislação provisória - após registro no "Livro do Estrangeiro"3 (CONGRESO NACIONAL DE LA REPÚBLICA DOMINICANA, 2014). No entanto, as medidas implementadas pelo Estado dominicano foram pouco efetivas para a resolução do problema - devido às amplas exigências, curtos prazos e altas taxas (BULAMAH, 2015) -, mantendo na situação de apatridia os indivíduos afetados.

A ausência de nacionalidade, como assentado nas normas internacionais, limita o acesso a direitos humanos. Destarte, a apatridia imposta na RD constitui-se um 'genocídio civil'4, uma vez que milhares de pessoas, antes dominicanas, “morreram” civilmente: estão impedidas de estudar, votar, viajar, adquirir propriedade, abrir contas bancárias, aceder os sistemas de saúde e de previdência, etc. A falta de documentação também torna tais indivíduos vulneráveis a detenções arbitrárias, a deportações, e a uma sorte de violações.

Ao fim do período de moratória das deportações de imigrantes em situação irregular previsto durante a aplicação do PNRE, a RD iniciou um processo de deportações em larga escala ${ }^{5}$. As estatísticas parciais apontam que cerca de 46 mil haitianos foram deportados apenas nos primeiros seis meses de 2017 (VENTURA, 2017), e pelo menos outras 66 mil retornaram "espontaneamente" ao país de origem (AMNESTY INTERNATIONAL, 2016).

Muitos descendentes de haitianos nascidos em território dominicano foram deportados sem nunca sequer terem ido ao Haiti, sem ter conexões com o país ou falar o idioma. O mais alarmante é que aproximadamente 2.000 pessoas das que foram expulsas em situação de vulnerabilidade - ou que retornaram “espontaneamente” - se estabeleceram em acampamentos nos arredores da cidade

\footnotetext{
${ }^{2}$ Não se previa, contudo, a restauração imediata da nacionalidade dominicana, demandando uma análise da JCE para validar cada certidão de nascimento individualmente. Aplicava-se também somente às pessoas nascidas antes de 18 de abril de 2007 - quando a JCE passou a emitir as atas de nascimento cor-de-rosa. Assim, os nascidos desde então e até 26 de janeiro de 2010 - data de promulgação da nova constituição - foram excluídos de qualquer possibilidade de restituição de nacionalidade (MORAES, 2017).

3 “Apenas 8.755 pessoas conseguiram solicitar seu registro como estrangeiro no período imposto, obtendo a perspectiva de ter acesso ao processo de naturalização especial - sendo que apenas 6.545 tiveram seus arquivos aprovados (AMNESTY INTERNATIONAL, 2018; ZARZUELA, 2015). O segundo grupo correspondia a 53.438 pessoas, ou seja, 83\% desse contingente não conseguiu beneficiar-se dos procedimentos previstos e permaneceram sem solução de fato para a privação de nacionalidade (AMNESTY INTERNATIONAL, 2018).

${ }^{4} \mathrm{O}$ termo genocídio civil é amplamente utilizado pela mídia dominicana, assim como pelas organizações não governamentais do país que reivindicam o direito à nacionalidade a dominicanos de ascendência haitiana.

${ }^{5}$ A República Dominicana tem um histórico em deportações coletivas de haitianos e haitianas, e seus descendentes. Os processos dominicanos de deportações são conhecidos pela ausência de análise individual, de respeito ao processo legal e do direito de apelação. Organizações de direitos humanos dominicanas e haitianas, ainda, documentaram uma série de deportações de pessoas que tinham o direito de usufruir do PNRE e de pessoas com direito à nacionalidade dominicana durante o período de moratória.
} 
haitiana de Anse-à-Pitres, ao sul da fronteira com a RD. Nos campos, as pessoas vivem em tendas improvisadas, e experienciam condições de vida degradantes: o acesso a serviços essenciais como água, alimentação, educação e saúde é restrito ou inexistente (HUMAN RIGHTS WATCH, 2016; AMNESTY INTERNATIONAL, 2016).

A violação dos direitos humanos dessas pessoas foi repudiada mais uma vez pela Corte Interamericana de Direitos Humanos em 2014. No caso das "Pessoas Dominicanas e Haitianas expulsas vs. República Dominicana”, o Tribunal de San José ratificou o entendimento consagrado no processo de 2005 e insistiu que a situação irregular de genitores imigrantes no território dominicano não pode ser herdada pelos descendentes. A Corte ainda atestou que a Sentença TC 168-2013 é discriminatória de fato, uma vez que é aplicada a um grupo específico que foi desproporcionalmente afetado pela introdução do critério diferenciado (CORTE INTERAMERICANA DE DIREITOS HUMANOS, 2014, p. 113). Finalmente, determinou que o governo dominicano tomasse as medidas cabíveis e imediatas para fulminar os efeitos legais da decisão TC 168-2013 do Tribunal Constitucional.

Novamente, contudo, a RD desconsiderou a decisão da Corte de San José. Como não bastasse, na sequência, o Tribunal Nacional prolatou sentença atestando a inconstitucionalidade do instrumento de adesão à competência da Corte Interamericana e, por fim, afirmou que a RD nunca esteve sob a jurisdição da mesma (TRIBUNAL CONSTITUCIONAL DE LA REPÚBLICA DOMINICANA, 2014).

O Acórdão do Tribunal Constitucional definiu a nacionalidade dominicana a partir do contexto migratório e, sobretudo, radicando-se em critérios históricos que legitimaram a discriminação racial contra haitianos, conforme será explicitado na sequência. Nesse sentido, é impossível compreender as problemáticas existentes entre a RD e o Haiti sem analisar as relações entre os dois Estados desde o tempo colonial. Afinal, a apatridia é um dos resultados da exploração colonial cujo elemento estruturante é a raça (QUIJANO, 2005), que, por sua vez, validou a dominação europeia e provocou segregações entre haitianos e dominicanos, consoante será explanado no próximo tópico.

\section{COLONIZAÇÃO E LIBERTAÇÃO NA ILHA DE HISPANIOLA}

A chamada La Española - a ilha antilhana compartilhada pela República do Haiti e pela RD - foi ocupada pelos espanhóis em dezembro de 1492. Seja por meio da resistência, das epidemias ou 
do trabalho compulsório, os indígenas foram dizimados, não meramente na ilha de Hispaniola ${ }^{6}$, mas em toda a região das Antilhas. Paulatinamente, os espanhóis introduziram os africanos na ilha para substituírem os nativos na extração de metais preciosos e na ainda tímida produção de açúcar.

Santo Domingo configurou-se um centro político, religioso e cultural no Caribe espanhol até o século XVIII. Economicamente, contudo, a produção de açúcar não se sustentou - passando a colapsar já em 1582 - e a presença de metais preciosos na ilha mostrou-se exígua (MOYA PONS, 1987). Nesse sentido, a Coroa espanhola passou a dirigir a sua ambição colonial, nos anos seguintes, para o continente, cessando em parte a colonização da ilha de Hispaniola e abandonando completamente, inclusive, a porção oeste da ilha (GRONDIN, 1985). Os franceses voltaram-se à região desocupada pelos espanhóis em 1630 e rumaram ao leste, dominando novos territórios. Por fim, em 1697, por meio do Tratado de Ryswick, a Espanha cedeu aos franceses a parte ocidental de Hispaniola, que passou a ser chamada de Saint-Domingue.

A hegemonia açucareira no Século XIX coube à França, e Saint-Domingue tornou-se a colônia mais rica e produtiva do mundo (AZEVEDO; HERBOLD, 1986; GRONDIN, 1985). Às vésperas da Revolução em Saint-Domingue, a "Pérola das Antilhas" exportava mais açúcar do que Jamaica, Brasil e Cuba juntos e a metade de toda a produção de café mundial (DUBOIS, 2004). Sabese, porém, que esse potente sistema era mantido em funcionamento às custas da mão de obra escravizada e, mais ainda, que o tráfico negreiro era um negócio tão rentável quanto a produção de açúcar.

A escravidão foi o motor da prosperidade do sistema econômico que enriqueceu a Europa e causou graves sequelas nas Américas e na África. Estima-se que, entre os séculos XVII e XVIII, foram trazidos em torno de 10 milhões de negros ao Caribe com o intuito de empregá-los como o “combustível biológico” da economia colonial (AZEVEDO; HERBOLD, 1986). A ilha de Hispaniola figurou como um dos principais pontos de desembarque do tráfico Atlântico no Caribe e a colônia de Saint-Domingue recebeu quase $10 \%$ do volume total de escravizados da região (DUBOIS, 2004).

A colonização francesa em Saint-Domingue fora estruturada e hierarquizada seguindo-se ditames econômicos, sociais e, principalmente, raciais. Entretanto, até mesmo para os padrões da época, as condições dos africanos nas plantações de açúcar e café de Saint-Domingue eram brutais, com trabalho exaustivo, humilhações e alta taxa de mortalidade (DUBOIS, 2004). Já a colônia

\footnotetext{
${ }^{6} \mathrm{O}$ território em questão apresenta diferentes denominações, que comumente se confundem entre si. Com o intuito de evitar dúvidas, serão definidos nomes diferentes para cada circunstância. Quando mensurado pelo seu total, utilizar-seão as denominações ilha de Hispaniola e La Española, ao passo que a porção espanhola da ilha será referenciada como Santo Domingo e a parte francesa por Saint-Domingue.
} 
espanhola, que não desenvolvera um sistema de plantation escravista, trouxe 48 vezes menos negros do que a sua vizinha Saint-Domingue (PONS, 2012). A concentração de escravizados e o índice de produtividade em Santo Domingo nunca se igualou ao vizinho francês. No século XVII, conhecido como o "século da miséria” em Santo Domingo, “a distância material entre escravos e mestres era tão pequena que pode ser até negligenciada” (CANDELARIO, 2007, p. 11). Os escravizados permaneceram, no entanto, a principal fonte de trabalho em Santo Domingo, seja nas plantações remanescentes, nas fazendas de gado ou na lida doméstica.

Entretanto, a escravidão nas sociedades pecuárias provou-se distinta das verificadas nas sociedades de plantation. O trabalho exigido dos escravizados na colônia espanhola era menos extenuante do que o realizado nas plantações de cana-de-açúcar (GATES JR., 2014). A escravidão em Santo Domingo, ainda que violenta, diferia de outras sociedades escravocratas. Já que os colonos não possuíam recursos para adquirir novos escravizados, o tratamento dado aos negros era consideravelmente menos cruel. Assim, a tensão entre brancos e negros era menor do que a encontrada em Saint-Domingue; todavia, não era inexistente. Apesar da proximidade entre negros e brancos, as relações entre estes nunca, de fato, eram praticadas em situação de igualdade. É importante ressaltar que o discurso colonial permanecia, assim como as relações desiguais entre senhores e escravizados.

Ao final do século XVIII, apenas 15\% da população negra em Santo Domingo permanecia escravizada (DUBOIS, 2004). Por fim, alguns conseguiram adentrar no funcionalismo colonial, ocupando funções eclesiásticas e postos no exército. Gates Jr. (2014, p. 180) comenta que alguns mestiços - chamados de brancos da terra - assumiam com deleite tais ofícios e, orgulhosos de servir à Coroa Espanhola, “chegavam a fazer anteceder à sua assinatura, em cartas e documentos oficiais, a expressão 'Dado na espanholíssima e mui leal cidade de São Domingos’”. Nesse panorama, para Moya Pons (apud GATES JR., 2014, p. 180), essas situações “criavam uma superestrutura ideológica de hispanidade, por mais escura que fosse a cor da pele” desses mestiços.

Em suma, os escravizados de Santo Domingo sentiam-se mais próximos de seus senhores e de sua cultura, ao passo que os escravizados de Saint-Domingue, em geral, rechaçavam a França e os franceses. Para Gates Jr. (2014, p. 182), os escravizados foram incorporados à sociedade dominicana de forma tão extraordinária que "se desenvolveu, aos poucos, uma sociedade muito mais voltada para o seu passado branco, europeu e colonial do que para a herança africana ou para a nação negra que 
nasceu de confrontos violentos no oeste da ilha"7 . Ao contrário, a prosperidade econômica da "Pérola das Antilhas” no século XVIII foi garantida graças a um sistema discriminatório que submetia os negros a abusos e barbáries que ratificavam "os complexos de superioridade e inferioridade racial, construídos como verdade inconteste pelo ideário ocidental” (SCARAMAL, 2006, p. 23).

Nesse contexto, o conjunto de ideias das Revoluções Francesa de 1789 e Americana de 1776 incitou a elite francesa e, também, os escravizados de Saint-Domingue a vislumbrar as possibilidades do fim do sistema colonial. Não obstante, ao passo que os brancos pleiteavam ampliar a sua autonomia política, os negros demandavam a execução dos ideais de igualdade e liberdade. Apoiados nesses princípios, os haitianos deram início, em 1791, às lutas pela libertação que foram compostas por numerosas revoltas. James (2000) relata que os ataques nas Planícies do Norte transformavam as plantações de açúcar, o símbolo da sua opressão e sofrimento, numa muralha de chamas:

Os escravos destruíam sem cansar [...] buscavam a salvação da maneira mais óbvia: pela destruição daquilo que causara o seu sofrimento; e se destruíram muito era porque haviam muito sofrido. Eles sabiam que enquanto essas fazendas permanecessem de pé o seu destino seria trabalhar nelas até o esgotamento. A única coisa a fazer era destruí-las. De seus senhores, eles haviam recebido a violação, a tortura, e à menor provocação, a morte. Pagaram na mesma moeda. Por dois séculos, a civilização mais evoluída mostrou-lhes que o poder era usado para descarregar a sua vontade sobre aqueles que controlava. Agora que detinham o poder, fizeram como haviam sido ensinados. (JAMES, 2000, p. 93).

Em janeiro de 1793 Inglaterra e Espanha declararam guerra à França. A Inglaterra ambicionava as vantagens de atender aos pedidos de defender a elite colonial francesa - o monopólio do açúcar, do anil, do café e do algodão - e a Espanha almejava recuperar a colônia que havia perdido anteriormente. Assim, um novo ingrediente era adicionado ao conflito de Saint-Domingue, tornandose uma guerra internacional (DUBOIS, 2004).

A expulsão definitiva dos inimigos exteriores da colônia francesa viria sob a liderança de Toussaint L'Ouverture: um ex-escravizado, letrado e nascido na colônia, que fora liberto já em 1777, e que emergiu como uma liderança capaz de unificar os haitianos em prol da liberdade (JAMES, 2000; DUBOIS, 2004). As tropas inglesas, famosas por derrotar a “Armada Invencível”, foram vencidas pela capacidade militar dos 48 mil negros capitaneados por L'Ouverture que, em janeiro de 1801, ocupou Santo Domingo (JAMES, 2000; PEÑA, 2012; SCARAMAL, 2006).

\footnotetext{
${ }^{7}$ Alguns historiadores dominicanos - como Frank Moya Pons e Juan Bosh - argumentam que uma série de fenômenos anômalos na história político-econômica de Santo Domingo é responsável por essa distinta formação sócio-racial: a curta duração e a importância da escravidão de plantation, as grandes depopulações causadas pela emigração branca, o empobrecimento dos colonos espanhóis e crioulos durante as “devastações” e a síncrona dependência de negros e mulatos nas forças armadas e nas estruturas religiosas (CANDELARIO, 2007).
} 
Em julho de 1801, L’Ouverture convocou a Assembleia e aprovou a primeira constituição da ilha une et indivisible, aboliu a escravidão e declarou-se governador de Saint-Domingue. Por consequência, a França, sob o comando de Bonaparte, tentou restaurar o controle da ilha e da escravatura por meio da força armada que fora composta por 86 navios e cerca de 50 mil veteranos de guerra. Uma emboscada em junho de 1802 resultou na prisão do líder haitiano e sua eventual morte um ano depois. Consequentemente, um governo francês foi estabelecido e logo fora restaurada a escravidão, fato que motivou a reação massiva dos negros da ilha (JAMES, 2000; SCARAMAL, 2006). Os ex-escravizados retomaram a colônia e massacraram "homens, mulheres e crianças, enfim, todos os brancos que caíram em suas mãos” (JAMES, 2000, p. 274). Em 31 de dezembro de 1804, Dessalines $^{8}$ declarou a independência, adotou o nome indígena taíno 'Haiti' e decretou, por fim, a liberdade aos haitianos.

O Haiti foi a segunda colônia a se separar da metrópole nas Américas - logo depois dos Estados Unidos - e a primeira nação negra independente do mundo (HOWARD, 2007). Os exescravizados tornaram-se governantes, e os brancos foram derrotados. Isso representou uma inversão da ordem inconcebível aos olhos do mundo dito civilizado, que justificava a escravização do negro em decorrência da "superioridade branca”. A mudança de tal ordem se concebe na ideia de caos para o colonizador. E, como ele não aceita outra estrutura social, a criação de um mundo diferente, o Haiti passa a ser associado à imoralidade, ao caos e à barbárie, e tal contexto justificaria as ações seguintes das potências coloniais (SCARAMAL, 2006). Para Aníbal Quijano (2005, p. 134), a Revolução Haitiana "foi um caso excepcional onde se produziu, no mesmo movimento histórico, uma revolução nacional, social e racial. Quer dizer, uma descolonização real e global do poder”. A Revolução Haitiana tornaria visível as contradições filosóficas do Iluminismo, como nenhum outro evento jamais fez; além disso, redefiniu o significado de liberdade, expandindo-a universalmente a todos os seres humanos (FICK, 2004). Ao assumirem-se serem humanos, os haitianos “[...] desafiaram as noções reinantes de humanidade, de Homem e Razão, ou seu acesso a faculdades e capacidades humanas” (GROVOGUI, 2006, p. 187).

Contudo, na sequência o Haiti foi alvo de isolamento político e de um boicote econômico gravíssimo por parte das potências da época (DUBOIS, 2004). A França apenas reconheceu a independência do Haiti em 1825, após a negociação de uma indenização pelas “perdas” relativas à independência da ex-colônia. O chamado “Débito da Independência” causou ao Haiti sérios danos econômicos, ao impor uma dívida absurda e indevida ao Estado recém-nascido, tornando-se um dos

\footnotetext{
${ }^{8}$ Jean Jacques Dessalines foi um ex-escravizado e líder da Revolução Haitiana. Após a captura de Toussaint, comandou o exército negro e substituiu a bandeira francesa por outra azul e vermelha, com o lema "liberdade ou morte”.
} 
principais motivos do atraso econômico nos séculos seguintes. Os conflitos devastaram as plantações de cana-de-açúcar, marcando o início da derrocada da Pérola das Antilhas - e que o tornou o país mais pobre das Américas (SILVA; PEROTTO, 2018).

A RD, em contrapartida, transitaria por um processo distinto de independência, porém interligado com os acontecimentos do Estado vizinho. A escravidão no território dominicano foi abolida duas vezes, não como resultado de forças abolicionistas ou por revolta liderada por escravizados, mas em decorrência de duas invasões militares haitianas - L’Ouverture em 1801, e Jean Pierre Boyer em 1822 (MOYA PONS, 2009). Antes, em 1795, a colônia espanhola foi cedida à França na sequência da derrota da Espanha na guerra europeia. A população negou-se a submeter-se ao novo domínio e deflagrou uma série de lutas contra a colônia francesa, em um primeiro momento e, a partir de 1804, contra a República do Haiti.

Apesar de Santo Domingo não se constituir como uma grande colônia escravista, uma possível abolição da escravatura pelas forças de Saint-Domingue era uma preocupação para aqueles que há tanto se beneficiavam desse sistema de opressão. Ainda, Peña (2012, p. 26) aponta que a alta classe encarava a propriedade de escravizados como "um direito que eles tinham como 'brancos"”. Com a chegada de Toussaint em São Domingos, a temida abolição da escravatura foi automaticamente imposta na Constituição promulgada em agosto de 1801, determinando que todos seriam livres (JAMES, 2000, p. 243). Tal iniciativa desagradou as elites de Santo Domingo, que receavam pela perda de seus privilégios e de, consequentemente, serem subordinadas aos negros de Saint-Domingue (GRONDIN, 1985; PEÑA, 2012). Assim, a população se uniu às tropas francesas e a invasão de Toussaint durou menos de um ano em Santo Domingo. Na sequência, a escravidão foi reintroduzida (MOYA PONS, 2009).

A ocupação francesa durou pouco em Santo Domingo. Em 1808, os criollos e os espanhóis se rebelaram e o território voltou para o domínio espanhol. A metrópole não conseguiu reestabelecer de fato o seu domínio sob a região, que proclamou independência adotando o nome Estado Independente do Haiti Espanhol, em 1821. Sucessivamente, o presidente do Haiti, Jean-Pierre Boyer, temendo que a fronteira leste fosse utilizada como um ponto de entrada pelas forças europeias, ordenou a terceira investida militar haitiana no território dominicano (GATES JR., 2014; PEÑA, 2012). Boyer nacionalizou terras privadas e, novamente, aboliu a escravidão: "sobre esse solo de liberdade, não há mais escravos” (MOYA PONS, 2009). Ainda, durante duas décadas da ocupação, a nação haitiana procuraria extrair riquezas a fim de amortizar a indenização que a França impôs pela independência. A violência e a dominação geraram, nesse período, ressentimento e temor em relação a haitianos (GATES JR., 2014; YRI, 2008). 
A redistribuição de terras e o fim da escravidão enfureceu as camadas mais ricas que, em 27 de fevereiro de 1844, proclamaram a independência. Em seguida, o novo Estado buscou o reconhecimento internacional, definindo-se como nação de brancos, mestiços e índios, além de espanhola e católica - claramente distanciando-se da nação negra vizinha (PEÑA, 2012). Todavia, as dificuldades enfrentadas impulsionaram o governo dominicano a solicitar a reincorporação do país à Espanha em 1861. O período provincial não durou muito e, em agosto de 1863, a Guerra da Restauração explodiu: a República Dominicana, por fim, em 1865, declarava-se independente pela terceira e última vez (DOMINICANA ONLINE, 2017; PEÑA, 2012; PORTAL OFICIAL DE LA REPÚBLICA DOMINICANA, 2014).

A partir de então, o Estado dominicano despontou economicamente e sua população ultrapassou o número de habitantes do outro lado da ilha. Ao mesmo tempo, o Haiti - arruinado pela guerra de independência, enfraquecido pelo bloqueio externo e por disputas internas de poder adentrava em uma conjuntura de decadência alarmante. Para além do aspecto econômico, os processos históricos que conduziram à independência dos dois países acentuaram, da mesma forma, suas diferenças sociais e culturais. A RD cultivou uma tradição indígena e europeia, ressaltando uma herança espanhola, enquanto o Haiti foi o primeiro país a fundar uma república negra com heranças africanas (HOWARD, 2007; PEÑA, 2012).

No século XIX, inicia-se um período de dominação dos Estados Unidos na ilha de Hispaniola. A ocupação imperialista não alterou, contudo, as diferenciações econômicas e sociais dos dois países; ao contrário, viria a acentuá-las. A RD passaria por mudanças estruturais atreladas ao desenvolvimento da indústria açucareira, ao passo que o enfraquecido Haiti não receberia nem metade dos investimentos injetados no país vizinho (AZEVEDO; HERBOLD, 1986). Tais circunstâncias incentivaram milhares de haitianos a voltaram-se à RD, em busca de oportunidades, conforme anteriormente retratado. Na década de 1980, inobstante a crise no setor açucareiro, a evasão de trabalhadores haitianos para a RD prosseguiu, porém, realocada para outros setores produtivos e expandida pelo território nacional ${ }^{9}$ (MARQUÉZ, 2012), o que fez aflorar o sentimento anti-haitiano.

\footnotetext{
${ }^{9}$ Em 2012, 5.4\% da população total da República Dominicana era constituída de imigrantes, cerca de 525 mil pessoas de mais de 60 nacionalidades diferentes. Desse total, 87.3\% eram nacionais do Haiti. Além disso, aponta-se a presença de 244.151 descendentes diretos de imigrantes na República Dominicana - ou seja, 2,5\% da população total do país. Destes, 86\% são de origem haitiana, ao passo que 14\% têm outras origens - não especificadas no estudo (OFICINA NACIONAL DE ESTADÍSTICAS, 2013).
} 


\section{A CONSTRUÇÃO DA DISCURSIVIDADE ANTI-HAITIANA: O HAITI COMO “LOCUS DA BARBÁRIE”}

A submissão das populações colonizadas foi viabilizada mediante um aparato de poder que alcançou tanto os campos materiais, como os imateriais. Para além da violência física, o colonizador se utilizou da agressão simbólica por meio do discurso, da linguagem e da consciência (MBEMBE, 2001; SAID, 2005). Nesse sentido, as hierarquizações construídas entre o chamado "Velho” e o “Novo” Mundo foram essenciais para o exercício da dominação colonial que se valeu de binarismos. A invenção de um suposto "choque de culturas" se consubstanciou por meio do discurso de depreciação e degeneração que resultou na desconstrução e a posterior construção da identidade do “Outro" (BHABHA, 1991).

A própria ideia de raça foi uma criação destinada a conferir legitimidade às relações de subjugação postas pela conquista. Neste sentido, atesta Quijano:

A expansão do colonialismo europeu ao resto do mundo conduziu à elaboração da perspectiva eurocêntrica do conhecimento e com ela à elaboração teórica da ideia de raça como naturalização dessas relações coloniais de dominação entre europeus e não-europeus. [...]. Desde então, [a raça] demonstrou ser o mais eficaz e durável instrumento de dominação social universal (QUIJANO, 2005, p. 118).

Ou seja, a classificação e hierarquização racial, que se mantêm na contemporaneidade, nasceu para sustentar o sistema de dominação colonial que propiciou a naturalização das pretensas inferioridades por meio da atribuição de funções e lugares subalternos de acordo com marcadores fenotípicos (QUIJANO, 2005). As teorias e práticas de hierarquização racial, que desumanizam o Outro, surgiram para assegurar o empreendimento colonial e justificar escravidão. A partir dela foi estabelecida uma teia de relações de poder baseada na preservação dos privilégios de alguns e na manutenção do sistema capitalista. A noção do “colonizador-civilizador” X o “colonizado-bárbaro” foi fundada pelo componente racial, que se desdobrou em práticas racistas e etnocêntricas norteadoras das relações de dominação entre colonizadores e escravizados. Assim, o discurso colonial não apenas forja representações sobre o Outro, o colonizado, visto como bestial, antropófago, a partir de delimitações raciais, culturais e históricas, como também repudia as diferenças, a fim de justificar a conquista. Nesse sentido, a historiografia colonial haitiana é o primeiro capítulo de uma tradição antihaitiana que ainda se vê perpetuada no presente (BHABHA, 1986; DUBOIS, 2004; SCARAMAL, 2006; VASCONCELOS, 2015).

De fato, o fim do colonialismo configurou-se como a primeira fase do processo de descolonização. A segunda etapa da descolonização é a decolonialidade, que aponta para a urgência da libertação dos ranços do colonialismo. A colonialidade surge do colonialismo, e se perpetua após 
o fim deste com a reprodução de um padrão de poder e relações sociais fundadas nas diferenças raciais. Como resultado, o mundo do começo do século XXI necessita de uma decolonialidade que complemente a descolonização deflagrada nos séculos anteriores (CASTRO-GÓMEZ; GROSFOGUEL, 2007).

Entretanto, a dominação colonial não se deu sem resistências, que provocaram fissuras no interior do próprio sistema. A mais importante delas foi a Revolução Haitiana, que não apenas sinalizou o advento da primeira nação negra do mundo, mas também é um marco da repulsa ao povo haitiano (SANTANA, 2003; SCARAMAL, 2006; VASCONCELOS, 2015). Após a Revolução se desenvolveu uma discursividade anti-haitiana de caráter degenerativo, enunciada não apenas pela metrópole francesa, mas por outras potências colonizadoras que, para tentar salvar o status quo colonial, induziu a praticamente todos os Estados ocidentais a não reconhecerem o Haiti como uma nação legítima (GATES JR., 2014).

A proclamação de independência por ex-escravizados atentou contra os pilares do sistema colonial, e funcionou como um alerta de perigo para as demais colônias. A insurgência dos negros contra as violências do sistema colonial foi recebida como uma afronta pela mesma ‘civilização’ que submeteu o indivíduo negro à escravidão, à miséria e à desumanidade. Essa inversão da ordem amplificou a construção discursiva de uma identidade haitiana como sendo bárbara. Assim foi que a “apoteose da independência se transformou em maldição da independência” (FANON, 1968). Um país onde os escravizados haviam tomado o poder a partir do massacre contra os brancos seria uma garantia da personificação das teorias de superioridade e uma prova inconteste de que os negros estavam fadados à condição de barbárie natural (SANTANA, 2003; SCARAMAL, 2006; VASCONCELOS, 2015).

O Haiti passou, como atesta Santana (2003, p. 59), a representar o “lócus da barbárie por excelência” e, portanto, motivo de repulsa e de reprovação internacional que, aliás, segue vigente. Ainda, as estratégias dos novos governantes haitianos de expansão para o leste da ilha de Hispaniola para impedir que a fronteira com a RD fosse violada para restabelecer a colonização foram essenciais ao fortalecimento dos discursos anti-haitianistas (MOYA PONS, 2013; SANTANA, 2003; SCARAMAL, 2006; VASCONCELOS, 2015).

A discursividade anti-haitiana foi ratificada em publicações que descreviam a natureza, a cultura e o povo como seres exóticos e insignificantes. A obra Hayti; Or, the Black Republic (1884) do cônsul britânico Sir Spencer Saint John é concebida como a narrativa mais depreciativa já escrita sobre o país. O autor retrata o Haiti como uma nação em decadência, “um país a ser evitado, arruinado por uma série de políticos egoístas, sem honestidade ou patriotismo, contentes em permitir que as 
pessoas se afundem em condições de uma tribo africana” (SPENSER, 1889, p. 20). O haitiano passou a ser representado como bárbaro, desonesto, selvagem, insolente e incapaz de trilhar os caminhos do progresso europeu, mesmo convivendo com os seus "mestres" por tanto tempo.

A todas as críticas acerca do Haiti se somam a suposta inépcia negra para o autogoverno, como se registra na citação de Spenser (1889, p. 134-135):

[...] quanto maior minha experiência [no país], menor achei a capacidade do negro de manter uma posição independente. Enquanto ele for impulsionado pelo contato com o homem branco, como na parte sul dos Estados Unidos, ele fica bem. Mas o liberte de toda essa influência, como no Haiti, e ele não mostra sinais de melhoria; pelo contrário, ele está gradualmente retrocedendo para os costumes tribais africanos, [...] eu agora concordo com aqueles que negam que o negro possa originar uma civilização, e que, mesmo com a melhor educação, ele permanece como um tipo inferior do homem. Ele ainda se mostrou totalmente incapaz de autogoverno e incapaz, como um povo, de fazer qualquer progresso. [...] Raramente eles agem de motivos patrióticos.

Com Hayti; Or, the Black Republic, os discursos anti-haitianistas atingem seu ápice, ao passo que estabeleceram uma "tradição literária grotesca ou escandalosa sobre o Haiti"10 (VASCONCELOS, 2015, p. 56). Tais discursos foram utilizados como parte de uma estratégia de Estado para justificar uma intervenção “civilizadora” e militar estadunidense no país. Assim, a retratação enviesada da historicidade haitiana difundiu-se mundialmente, não se limitando ao terreno da ilha Hispaniola e aos seus polos de migração - como seus vizinhos antilhanos e estadunidenses. Os setores midiáticos - e também as produções hollywoodianas que retratam odiosamente o vodu e seus praticantes - ajudaram a disseminar essa visão do caos e do horror (SCARAMAL, 2006). Assim, a "Pérola das Antilhas” passou a ser sinônimo de miséria. Na França, designações comuns para o país caribenho incluem "nação patética” e "pedaço de África perdido no meio da Américas" (SCHWARTSMAN, 2010).

Durante o período perturbado da ocupação norte-americana, nasceu o movimento negritude, que ensejou reagir contra as convenções acerca da bestialidade dos haitianos e se propôs a ponderar as identidades haitianas a partir do reconhecimento da relevância da Revolução e da valorização das suas origens afrodescendentes (SANTANA, 2003; SCARAMAL, 2006; VASCONCELOS, 2015). Sincronicamente, na $\mathrm{RD}$, que também se encontrava sob a intervenção estadunidense - com o governo ditatorial de Trujillo -, um movimento contrário ganhava força: procurava-se ressignificar a identidade dominicana a partir de um viés sucessor da cultura hispânica no Caribe - "longe de tentar

\footnotetext{
${ }^{10}$ Nota-se aqui a publicação de outras obras que forneceram material aos discursos anti-haitianistas: When Black rules White: A journey across and about Hayti (1910), de H. Hesket Pichard; Le Roi blanc de la Gonâve - Le culte du vaudou en Haïti 1915-1929 (1932), de Faustin Wirkus; Magic Island (1929), de W. B. Seabrook; Cannibal Cousins (1932) e Black Bagdad (1933), de John H. Graige (HURBON, 1993, p. 72-75).
} 
resgatar suas raízes africanas” (VASCONCELOS, 2015, p. 57). Assim, Gates Jr. (2014, p. 198) afirma que os dominicanos passaram a conceber uma forte aversão aos haitianos, rejeitando sua cultura, sua língua e sua cor. Destarte, ser dominicano “[...] passou a significar, cada vez mais, não ser haitiano”.

O anti-haitianismo dominicano divide-se em duas vertentes: a histórica - que surge e se sustenta ao longo da evolução da historicidade dos dois povos - e a estatal - que se desenvolve a partir dessas historicidades, mas atrelada a políticas de Estado (MOYA PONS, 2013). É importante ressaltar que o anti-haitianismo dominicano tem em sua origem aspectos geográficos, políticos, sociais e culturais; contudo, para Lilón (2010, p. 288), a construtividade histórica se destaca nessa totalidade.

O historiador dominicano Moya Pons (2013) suscita que o anti-haitianismo histórico é derivado das más relações entre França e Espanha no século XVIII, assim como de seus respectivos colonos assentados na ilha Hispaniola. Essas tensões se degradam com a Revolução Haitiana, se agravam com a cessão de Santo Domingo à França em 1795 e atingem o ápice durante as invasões haitianas de 1801 e 1805. Estas figuram, certamente, como a "raiz histórica do anti-haitianismo na República Dominicana” (MOYA PONS, 2013).

A ocupação haitiana de 1822 conservou tais tensões e se prolongou até a proclamação da independência da República Dominicana em 1844 (GATES JR., 2014; MOYA PONS, 2013; VASCONCELOS, 2015; YRI, 2008). Nestas duas décadas de embates, o Estado dominicano transforma a memória das invasões haitianas em “propaganda de guerra” (MOYA PONS, 2013). A afirmação das diferenças raciais, religiosas, culturais e domésticas foi essencial para a edificação da nacionalidade dominicana, que tenderia a se alijar do Haiti. Assim, "ser dominicano durante a guerra de independência não era somente não ser haitiano, mas também ser anti-haitiano” (MOYA PONS, 2013).

O anti-haitianismo histórico nunca se dissipou, resistiu subjacentemente "através dos anos e segue vivo na entrada do século XX” (MOYA PONS, 2013). Moya Pons (2013) atesta que houve um soterramento desses sentimentos negativos contra os haitianos, durante a ocupação, devido à censura da imprensa nos dois países, que invisibilizou as campanhas anti-haitianas, mas não as extinguiu das entranhas da sociedade. Entretanto, o anti-haitianismo estatal esteve adormecido até o alvorecer do Estado trujillista, que se utilizou do anti-haitianismo histórico para atacar a população haitiana (MOYA PONS, 2013; YRI, 2008).

A partir da segunda fase do anti-haitianismo de Estado promovido por Trujillo, há um enfoque nas diferenças raciais e na superioridade dos dominicanos (MOYA PONS, 2013). Tal 
estratégia resulta na identificação do haitiano como inimigo fulcral da dominicanidade (GATES JR., 2014; MOYA PONS, 2013; SCARAMAL, 2006; VASCONCELOS, 2015; YRI, 2008) e introduz a questão da porosidade da fronteira RD-Haiti. Assim, era necessário enfatizar a autonomia política e cultural contra este "agressor imperialista e sangrento cuja obsessão é destruir seus vizinhos hispânicos que são amantes da paz, e como um veneno iminente que penetra gradualmente através dos poros da fronteira e que assim vai contaminando a nação dominicana” (DERBY; TURITS, 1993, p. 70-71).

Nesse contexto, o anti-haitianismo trujillista conheceu o apogeu entre dois e oito de outubro de 1937, quando foi promovido um massacre conhecido como El Corte ${ }^{11}$, que resultou na morte de milhares de haitianos e seus descendentes que viviam na região fronteiriça, colocando em prática um projeto de dominicanização dessa região a fim de conter tal “contaminação"12. Essa política foi expandida nos anos seguintes por meio da substituição de nomes de vilarejos - de nomes que aparentavam ser haitianos para nomes hispânicos -, da ampliação da escolarização pública com ênfase no idioma e em traços culturais hispânicos e, por fim, na criminalização das práticas de Vodu (WOODING; MOSELEY-WILLIAMS, 2004).

As discursividades de políticos e intelectuais dominicanos, como Joaquin Balaguer, notabilizaram o anti-haitianismo racial de Estado. Na obra La isla al revés: Haití y el destino dominicano, o autor empenha-se em construir uma dominicanidade por meio da depreciação da identidade de seus vizinhos. Autoimputando-se de imparcialidade, Balaguer (1983, p. 59) argumenta que Santo Domingo serviu como berço da "raça mais destacada espiritualmente e fisicamente" do continente americano, ao passo que o Haiti é identificado como uma nação de negros de "raça inferior”, “de práticas bárbaras” e com “tremendas deficiências morais” (BALAGUER, 1983, p. 3536). Segundo ele, o dominicano é:

pelo instinto de conservação, o povo mais espanhol e tradicionalista da América [...] a língua e a tradição hispânica foram, durante mais de um século, as únicas paredes que serviram de defesa contra a espantosa onda de cor e contra as forças desagradáveis que, desde 1795, têm

\footnotetext{
11 Também conhecido como El massacre de Perejil graças ao artifício utilizado pelos militares dominicanos para a identificação de haitianos: os faziam pronunciar a palavra perejil (salsa, em português). Os haitianos, em função da sua raiz linguística francesa, não conseguiam pronunciar a palavra corretamente, sendo facilmente identificáveis (VASCONCELOS, 2015, p. 58)

${ }^{12}$ Não há consenso na bibliografia acerca do número exato de pessoas mortas. As estimativas variam de 1 mil a 30 mil haitianos assassinados. Lilón (2010, p. 290), no entanto, destaca que grande parte dos historiadores traz uma estimativa de 10 mil mortos. Os únicos haitianos poupados, por ordem direta, foram aqueles que trabalhavam para as açucareiras norte-americanas em território dominicano. Outros tantos, ao chegar das tropas de Trujillo, conseguiram fugir pela fronteira ou foram salvos por dominicanos que os escondiam em suas casas (WOODING; MOSELEY-WILLIAMS, 2004).
} 
invadido, de forma ininterrupta e sistemática, o território dominicano (BALAGUER, 1983, p. 63).

Balaguer considera que a dominicanidade está em constante “perigo” pela ameaça negra. A presença haitiana seria uma enfermidade que corroeria a alma e a fisionomia espanhola. Para ele, a cultura haitiana é o "abismo moral que vem infectando" os dominicanos por meio da "penetração pacífica e constante que o país vem sofrendo desde 1801 até hoje” por intermédio da imigração - ou imperialismo biológico ${ }^{13}$ (BALAGUER, 1983, p. 50). Dessa forma, seria necessário interromper a imigração de indivíduos "não caucasianos ou não pertencentes às raças autóctones da América" (BALAGUER, 1983, p. 73).

O desenvolvimento do anti-haitianismo da República Dominicana não apenas moldou as relações entre seus habitantes e o Haiti, mas também alterou e dominou a sua própria identidade: “a aversão aos haitianos se tornou, por assim dizer, parte da alma dominicana” (GATES JR., 2014). Por conseguinte, muitos dominicanos rejeitam a cultura do Haiti, sua língua, suas ideias e até mesmo sua cor. A maioria dos dominicanos possui ascendência negra; contudo, poucos dominicanos se identificam como negros - cerca de 15\%; outros 58\% se classificam como “indígena”14 (LAPOP, 2014). Ser negro, contudo, refere-se ao Haiti, e não à África. Na RD “ninguém é negro, porque essa palavra é reservada para os haitianos [...]. Na verdade, se trata de negar tudo que seja haitiano" (GATES JR., 2014, p. 191). Entre alguns dominicanos, ser negro significa ser "pobre, sujo, inculto, ignorante, degenerado. Tudo o que pensavam sobre os haitianos tornou-se o que pensavam sobre ser negro”. (GATES JR., 2014, p. 117). Assim, a representação do haitiano na RD passou a ocupar o mesmo nível da representação dos negros pelos brancos. Dessa forma, percebe-se que a condição de apatridia imposta aos haitianos é uma tentativa de negar o pertencimento nacional àqueles que se considera diferente e inferior segundo a lógica da modernidade colonial.

\section{CONSIDERAÇÕES FINAIS}

As abordagens decoloniais e pós-coloniais são muito úteis como ferramentas de análise, pois permitem associar o racismo à tragédia de apatridia na RD. Elas oferecem algumas chaves de

\footnotetext{
${ }^{13}$ Ou seja, aquele imperialismo que não é imposto mediante a força, mas por meio da reprodução biológica.

${ }^{14}$ Ressalta-se que, desde 1981, não foram apuradas quaisquer características étnico-raciais ou linguísticas nos censos liberados pela Oficina Nacional de Estadística. Apenas em cinco dos censos disponíveis foi incluída uma pergunta sobre raça ou etnia (1920, 1935, 1950, 1960 e 1981), sendo que o último censo com a questão apenas catalogou os entrevistados como “dominicanos", "haitianos" e “outros”, de acordo com "las características físicas y acento al hablar", por determinação do entrevistador (OFICINA NACIONAL DE ESTADÍSTICAS, 2012).
} 
entendimento sobre os impactos da colonização na ilha Hispaniola e sobre a perpetuação da colonialidade nas decisões políticas, refletidas na promulgação de normas e nas práticas das instituições. No estudo em tela, é possível levantar ao menos quatro temas que podem ser explicados a partir das epistemologias críticas: a representação do Outro, a hierarquização fundada na raça, a negação do protagonismo dos Haitianos e, por fim, a reprodução da colonialidade nas elites dominicanas, que passam a se identificar como o colonizador.

A representação do Outro/haitiano enquanto bárbaro e inferior é uma das caras da construção da ideia de raça, que foi fundamental no processo de hierarquização das pessoas que serviu à dominação colonial. Como adverte Lynn Doty (1996), o empreendimento colonial surge como uma espécie de “obrigação” dos seres ditos superiores, ou seja, é o "fardo do homem branco", a quem foi concedida a missão de civilizar o colonizado, já que este necessitaria de ajuda dos salvadores ocidentais para alcançar as benesses da civilização. Assim, a desconstrução das outridades baseada em ideais iluministas seletivos, em crenças racistas de superioridade e concepções de mundo eugenistas justificaram a escravidão e a perpetração de barbáries jamais admitidas em solo metropolitano.

Como bem explicam Quijano e Wallerstein (1992), o eurocentrismo se consolidou por meio de condições materiais e simbólicas, que abrangem a conquista de territórios para colonização e a hierarquização das populações residentes, utilizando a cor da pele como critério primordial. A racialização foi um modo de inferiorização do não europeu, indispensável para naturalização das relações coloniais de dominação. Com o passar do tempo, foram incorporadas novas categorias hierarquizadoras que diferenciaram o europeu dos Outros, resultando em binarismos como fiel/infiel, civilizado/bárbaro e, mais tarde, desenvolvido/subdesenvolvido. Em resumo, há um catálogo de hierarquias epistêmicas, raciais, de gênero, de sexualidade, etc., forjadas pela Modernidade e que se constituíram como base fundante do imperialismo.

Entre essas hierarquias está, também, a invisibilização do protagonismo dos povos negros, bem exemplificado pela Revolução Haitiana, e que está conectada, entre outros, com a negativa de reconhecimento de loci de enunciação considerados marginais pelos impérios coloniais e que, consequentemente, contestam a validade da história universal (MIGNOLO, 2003). A proclamação de independência por ex-escravizados negros representou uma falha no sistema colonial, um “perigoso” exemplo para as demais colônias. Desse modo, era necessário reverter a ordem de entendimento do episódio e considerar a luta dos negros contra a exploração pelos brancos como sanguinária, um atestado de barbárie contra a mesma civilização que submeteu o colonizado à escravidão, à violência 
e à humilhação. Essa inversão da ordem amplificou a construção discursiva de uma identidade haitiana como sendo bárbara.

Por fim, além de afirmar que o leque de instrumentos que remetem à atribuição de nacionalidades, à concessão de passaportes e à demarcação de fronteiras são heranças coloniais, é necessário problematizar a reprodução das poderosas dinâmicas coloniais de poder nas ações das elites dominantes da RD. As dinâmicas racistas anti-haitianas, que são discursivas e materiais, tanto podem ser explicadas com auxílio do conceito de “nordomania”, formulado por José Henrique Rodó (1900) - que atesta para os riscos de dominação cultural, social e moral, originados da idolatria devotada ao Norte, combinando um sentimento de inferioridade com a fetichização daquilo que vinha da metrópoles -, como também podem ser associadas à potência avassaladora dos discursos e práticas coloniais que têm capacidade, inclusive, de promover uma inversão de papéis, quando o colonizado não consegue se desatar das amarras da alienação e aspira ocupar o lugar do colonizador (FANON, 1968). Ao contrário do Haiti, o Estado dominicano associou-se à uma identidade europeia, católica e branca, afastando-se das suas origens africanas. De fato, a dominicanidade foi construída, sobremaneira, a partir de uma ideologia de negação da sua negritude e de adesão à branquitude. Entre as consequências dessa lógica, figura a formulação de políticas migratórias racistas e restritivas que tem promovido o “genocídio civil” de milhares de descendentes de haitianos.

O paradoxo entre a necessidade da mão de obra haitiana e o anti-haitianismo estatal sobreviveu para além da ditadura de Trujillo, já que se prolongou nos governos de seus sucessores políticos, como Joaquín Balaguer e Juan Bosch, que, embora tenham sido democraticamente eleitos, fomentaram, igualmente, a discursividade racista. Assim, o anti-haitianismo na RD manifesta-se, para além da construção da identidade dominicana como oposta à haitiana, mas direta ou indiretamente por meio da marginalização dessas populações, na representação pejorativa de imigrantes haitianos nas mídias conservadoras e, enfim, na negação a direitos humanos, como o de possuir uma nacionalidade. Na condição de apátridas, esses indivíduos encontram-se no limbo - não existem para o Estado e não conseguem desfrutar de direitos básicos -, além de serem sujeitos a práticas de deportações.

Conclui-se, assim, que a desnacionalização, a negação da nacionalidade a descendentes de haitianos na RD, fazem parte de um processo histórico de hierarquização das subjetividades negras e de embargo às suas existências, que demonstram as persistentes interseções entre o racismo e a colonialidade. 


\section{REFERÊNCIAS}

ALTO COMISSARIADO DAS NAÇÕES UNIDAS PARA REFUGIADOS (ACNUR). Dominican Republic urged not to deport stateless Dominicans. 2015. Disponível em: https://bit.ly/33mbNP6. Acesso em: 26 abr. 2018.

AMNESTY INTERNATIONAL. "Where are we going to live?”: Migration and statelessness in Haiti and the Dominican Republic. 2016. Disponível em: https://bit.ly/2KwNs0m. Acesso em: 28 abr. 2018.

AMNESTY INTERNATIONAL. Report 2017/18: The State of the World's Human Rights. 2018. Disponível em: https://bit.ly/1EbOlCK. Acesso em: 28 abr. 2018.

AZEVEDO, Elizabeth R.; HERBOLD, Hildegard. Caribe: o paraíso submetido. Coleção Tudo é História. São Paulo: Editora Brasiliense, 1986.

BALAGUER, Joaquín. La isla al revés: Haití y el destino dominicano. Santo Domingo: Editora Corripio, 1983.

BHABHA, Homi. A questão do “outro": diferença, discriminação e o discurso do colonialismo. In: HOLLANDA, Heloisa Buarque (org.). Pós-modernismo e Política. Rio de Janeiro: Editora Rocco, 1991.

BULAMAH, Rodrigo Charafeddine. Deportações na República Dominicana. Le Monde, 3 set. 2015. Disponível em: https://bit.ly/2YRjZHv. Acesso em: 16 set. 2017.

CANDELARIO, Ginetta E. B. Black behind the ears: Dominican racial identity from museums to beauty shops. London: Duke University Press, 2007.

CASTRO-GÓMEZ, Santiago; GROSFOGUEL, Ramon. Giro decolonial, teoría crítica y pensamiento heterárquico. In: CASTRO-GÓMEZ, S.; GROSFOGUEL, R. Giro Decolonial: Reflexiones para una diversidad epistémica más allá del capitalismo global. Bogotá: Siglo del Hombre Editores; Universidad Central, Instituto de Estudios Sociales Contemporáneos y Pontificia Universidad Javeriana, Instituto Pensar, 2007. p. 9-22.

COMISSÃO INTERAMERICANA DE DIREITOS HUMANOS (CIDH). Report on the Situation of Human Rights in the Dominican Republic. OEA/Ser.L/V/II.104. 07/10/1999. Disponível em: https://bit.ly/2OLhId8. Acesso em: 19 jul. 2017.

CONGRESO NACIONAL DE LA REPÚBLICA DOMINICANA. Ley de inmigración No. 95 del 14 de abril de 1939. 1939. Disponível em: https://bit.ly/2Tfeq0x. Acesso em: 7 ago. 2017.

CONGRESO NACIONAL DE LA REPÚBLICA DOMINICANA. Ley de Migración No. 285-04. 2004. Disponível em: https://bit.ly/33i2P5j. Acesso em: 7 ago. 2017.

CONGRESO NACIONAL DE LA REPÚBLICA DOMINICANA. Ley No. 169-14 de 2014 que establece un régimen especial para personas nacidas en el territorio nacional inscritas irregularmente en el Registro Civil dominicano y sobre naturalización. 2014. Disponível em: https://bit.ly/2yM48LP. Acesso em: 16 set. 2017. 
CORTE INTERAMERICANA DE DIREITOS HUMANOS. Caso das Crianças Yean e Bosico v. República Dominicana. 2005. Disponível em: https://bit.ly/2KEw4H9. Acesso em: 8 ago. 2017.

CORTE INTERAMERICANA DE DIREITOS HUMANOS. Caso Personas dominicanas y haitianas expulsadas vs. República Dominicana. 2014. Disponível em: https://bit.ly/1tNIy3s. Acesso em: 8 ago. 2017.

DERBY, Robin L. H.; TURITS, Richard. Historias de terror y los terrores de la historia: la masacre haitiana de 1937 en la República Dominicana. Estudios Sociales. Ano XXVI, número 92, 1993.

DOMINICANA ONLINE, El portal de la República Dominicana. Annexation and Restoration. 2017. Disponível em: https://bit.ly/2yN6UAs. Acesso em: 3 set. 2017.

DUBOIS, Laurent. Avengers of the new world: The story of the Haitian revolution. Cambridge: The Belknap Press, 2004.

FANON, Frantz. Os Condenados da Terra. Rio de Janeiro: Civilização Brasileira, 1968.

FERGUSON, J. Migration in the Caribbean: Haiti, the Dominican Republic and beyond. Minority Rights Group. Londres, 2003. Disponível em: https://bit.ly/2YTZMNo. Acesso em: 2 ago. 2017.

FICK, Carolyn. Para uma (re)definição de liberdade: a Revolução no Haiti e os paradigmas da Liberdade e Igualdade. Estudos Afro-Asiáticos, ano 26, nº 2, 2004, p. 335-380.

GATES JR., Henry Louis. Os negros na América Latina. São Paulo: Companhia das Letras, 2014.

GRONDIN, Marcelo. Haiti: Cultura, poder e desenvolvimento. Coleção Tudo é História. São Paulo: Editora Brasiliense, 1985.

GROVOGUI, Siba N. Mind, body, and gut! Elements of a postcolonial human rights discourse. In: JONES, Branwen Gruffydd (ed). Decolonizing international relations. Plymouth: Rowman and Littlefield Publishers, 2006. p. 179-96.

HOWARD, David. Dominican Republic Spurns Haitian Migrants: Rejection of African Heritage Fuels Anti-Haitian Views. NACLA Report on the Americas, vol. 35, no. 2, 2007, p. 24-28.

HUMAN RIGHTS WATCH (HRW). Haití: Atrapadas en la pobreza miles de personas apátridas. 2016. Disponível em: https://bit.ly/2yIrjqu. Acesso em: 28 abril 2018.

HURBON, Laënnec. El bárbaro imaginario. Tradução Jorge Padín Videla. Ciudad de México: Fondo de Cultura Económica, 1993.

JAMES, C. L. R. Os jacobinos negros: Toussaint L’Ouverture e a revolução de São Domingos. São Paulo: Boitempo, 2000.

LAPOP. Cultura política de la democracia en República Dominicana y en las Américas, 2014: Gobernabilidad democrática a través de 10 años del Barómetro de las Américas. Vanderbilt University: 2014. Disponível em: https://bit.ly/2MNpkct. Acesso em: 14 set. 2017. 
LILÓN, Domingo. Inmigración, xenofobia y nación: el caso dominicano. Revista del CESLA, vol. 1, núm. 13, 2010, pp. 287-300. Uniwersytet Warszawski. Varsóvia, Polônia. Disponível em: https://bit.ly/2ON62qy. Acesso em: 4 set. 2017.

LYNN DOTY, Roxanne. Imperial Encounters: The Politics of Representation in North-South Relations. Minneapolis: Minesota Press, 1996.

MÁRQUEZ, Elba Y. Coria. Estudio Migratorio de República Dominicana. In: Estudio comparativo de la legislación y políticas migratorias en Centroamérica, México y República Dominicana. Cidade do México: Incedes; Sin Fronteras, 2012. p. 560-606.

MBEMBE, Achille. On the postcolony. Los Angeles: University of California Press, 2001.

MIGNOLO, Walter D. Histórias locais/Projetos globais: colonialidade, saberes subalternos e pensamento laminar. Tradução Solange Ribeiro de Oliveira. Belo Horizonte: Ed. UFMG, 2003.

MORAES, Thaís Guedes Alcoforado de. “O Haiti não é aqui”: Apatridia na República Dominicana e o direito à nacionalidade. 2017. Dissertação (Mestrado em Direito) - Universidade de Brasília, Brasília, 2017. Disponível em: https://bit.ly/31plavA. Acesso em: 8 set. 2017.

MOYA PONS, Frank. "Las Dos Aboliciones de la Esclavitud”. Historia Dominicana, 2009. Disponível em: https://bit.ly/2YPROZL. Acesso em: 3 nov. 2017.

MOYA PONS, Frank. Antihaitianismo Histórico y Antihaitianismo de Estado. Archivo OrbeQuince, Madrid, 2013. Disponível em: https://bit.ly/33e13SK. Acesso em: 2 ago. 2017.

MOYA PONS, Frank. Despues de Colon: trabajo, sociedade y politica em la economia del oro. Madrid: Alianza, 1987.

OFICINA NACIONAL DE ESTADÍSTICAS (ONE). La variable étnico racial en los censos nacionales de población en la República Dominicana. 2012. Disponível em: https://bit.ly/2M7GrWX. Acesso em: 2 set. 2017.

OFICINA NACIONAL DE ESTADÍSTICAS (ONE). Primera Encuesta Nacional de Inmigrantes en la República Dominicana (ENI-2012). 2013. Disponível em: https://bit.ly/2h1qNeG. Acesso em: 2 set. 2017.

PEÑA, Julissa. "Yo soy negro, pero negro blanco": Hispanicity, Antihaitianismo and Genocide in the Dominican Republic. 2012. Tese (Doutorado em Bachelor of Arts) - Wesleyan University, Middletown, Connecticut, 2012. Disponível em: https://bit.ly/31sUcTP. Acesso em: 17 ago. 2017.

PONS, José C. Migración africana y formación social en las Américas, 1500-2000. Revista de Indias, 2012, vol. LXXII, núm. 255, p. 321-348.

PORTAL OFICIAL DE LA REPÚBLICA DOMINICANA. História Dominicana. 2014. Disponível em: https://bit.ly/2ZHAy5T. Acesso em: 20 set. 2017.

PRESIDENCIA DE LA REPÚBLICA DOMINICANA. Decreto n. 327-13: Plan Nacional de Regularización de Extranjeros en situación migratoria irregular en la República Dominicana. 2013. Disponível em: https://bit.ly/2xWEmGJ. Acesso em: 20 set. 2017. 
QUIJANO, Aníbal. Colonialidade do poder, eurocentrismo e América Latina. In: LADNER, Edgardo (org.). A colonialidade do saber: eurocentrismo e ciências sociais. Perspectivas latinoamericanas. Buenos Aires: Colección Sur Sur, CLACSO, set. 2005, p. 117-138.

QUIJANO, Aníbal; WALLERSTEIN, Immanuel. La Americanidad como concepto, o América en el moderno sistema mundial. RICS, nº 44(4), p. 583-591, 1992.

REPÚBLICA DOMINICANA. Constitucion de la República Dominicana. 14 de agosto de 1994. Disponível em: https://bit.ly/2M7reoY. Acesso em: 10 out. 2017.

REPÚBLICA DOMINICANA. Constitucion de la República Dominicana. 2010. Disponível em: https://bit.ly/2YSOAEL. Acesso em: 2 ago. 2017.

RODÓ, Henrique. Ariel. 1900. Disponível em: https://bit.ly/2OMamWP. Acesso em: 20 de out. 2016.

SAID, Edward W. Orientalismo: “o Oriente como invenção do Ocidente”. São Paulo: Companhia das Letras, 2005.

SANTANA, Márcio A. de. Literatura e construção da comunidade imaginada haitiana: uma leitura de Jacques Stephen Alexis e Jacques Roumain (1915-1971). 2003. Dissertação (Mestrado em História) - Universidade Federal de Goiás, Goiânia, 2003. Disponível em: https://bit.ly/2TgfxwY. Acesso em: 7 ago. 2017.

SCARAMAL, Eliesse dos Santos Teixeira. Haiti: fenomenologia de uma barbárie. Goiânia: Cânone, 2006.

SCHWARTSMAN, Hélio. Graças ao açúcar “pedaço da África” já foi “pérola”. Folha de São Paulo, 14 jan. 2010. Disponível em: https://bit.ly/2Kpz0sd. Acesso em: 1 set. 2017.

SILVA, Karine de Souza; PEROTTO, Luiza L. N. A Zona do Não-Ser do Direito Internacional: Os Povos Negros e a Revolução Haitiana. Direito e Justiça: Reflexões Sociojurídicas, v. 18, p. 125153, 2018. Disponível em: https://bit.ly/2TeFooY. Acesso em: 3 maio 2019.

SPENSER, St. John. Hayti, or, the Black republic. New York: Scribner \& Welford, 1889. Disponível em: https://bit.ly/2M6XCIf. Acesso em: 20 out. 2017.

TRIBUNAL CONSTITUCIONAL DE LA REPÚBLICA DOMINICANA. Sentencia TC 0256-14. 2014. Disponível em: https://bit.ly/2ZJ5aEl. Acesso em: 22 ago. 2017.

TRIBUNAL CONSTITUCIONAL DE LA REPÚBLICA DOMINICANA. Sentencia TC/0168/13. 2013. Disponível em: https://bit.ly/33gvPdT. Acesso em: 22 ago. 2017.

VASCONCELOS, Alex Donizete. Anti-haitianismo: uma tradição de identidade haitiana? Universitas: Relações Internacionais, Brasília, v. 13, n. 2, p. 51-65, jul./dez. 2015. Disponível em: https://bit.ly/2TfE9Wy. Acesso em: 7 set. 2017.

VENTURA, Thomas. República Dominicana deporta mas de 46 mil haitianos em seis meses.

Diario Libre, Santo Domingo, 10 jul. 2017. Disponível em: https://bit.ly/2Teqlf4. Acesso em: 26 abr. 2018. 
WOODING, Bridget; MOSELEY-WILLIAMS, Richard. Needed but wanted: Haitian immigrants and their descendants in Dominican Republic. London: Catholic Institute for International Relations, 2004.

YRI, Jorgen. El bárbaro vago y la isla indivisible: La representación de lo haitiano en la oficialidad dominicana ejemplificada por la lectura de El ocaso de la nación dominicana y La isla al revés - Haití y el destino dominicano. 2008. Dissertação (Mestrado em Espanhol) - Universidad de Bergen, Bergen, 2008. Disponível em: https://bit.ly/2KIXylY. Acesso em: 12 set. 2017.

ZARZUELA, Alejandro Arias. Reforma migratória na República Dominicana. Le Monde, 7 dez 2015. Disponível em: https://bit.ly/2YE6Faw. Acesso em: 1 jul. 2017.

Professora nos Programas de Pós-Graduação em Direito (PPGD) e em Relações Internacionais (PPGRI) da Universidade Federal de Santa Catarina. Pesquisadora Produtividade em Pesquisa PQ CNPq. Coordenadora do Eirenè - Centro de Pesquisas e Práticas Pós-Coloniais e Decoloniais aplicadas às Relações Internacionais e ao Direito Internacional.E-mail: karine.silva@ufsc.br

Luísa Milioli de Amorim Bacharela em Relações Internacionais pela Universidade Federal de Santa Catarina. Pesquisadora no Eirenè - Centro de Pesquisas e Práticas Pós-Coloniais e Decoloniais aplicadas às Relações Internacionais e ao Direito Internacional. E-mail: luuisaamorim@gmail.com 